\title{
Individualized Teaching and Teaching Process Evaluation for International Trade Students Based on Information Techniques
}

\author{
https://doi.org/10.3991/ijet.v14i23.12301 \\ Yanan Zhao \\ School of Economics, Shenyang University, Shenyang 110044, China \\ syuinte126.com
}

\begin{abstract}
With the boom in information technology, countries around the world are competing the information the education industry. However, there is not yet a well-established standard to evaluate students' capabilities in the teaching process based on information techniques. To solve the problem, this paper introduces the latest information techniques, such as big data and cloud computing, into the teaching of international trade, designs an individualized teaching system based on student portrait, and constructs an intelligent evaluation system of the teaching process. On this basis, several suggestions were put forward on the reform of the training model of international trade students. This research provides new insights on the evaluation and improvement of the teaching effect in the department of international trade.
\end{abstract}

Keywords-Student portrait, teaching process evaluation, education informatization, individualized teaching

\section{Introduction}

The 21st century is the age of information and knowledge economy. Unlike traditional economy, the knowledge economy depends on the quantity, quality, and accessibility of the information available, rather than the means of production. With the boom of information technology, the knowledge economy is on the track to dominate the world economy [1]. Similar to knowledge economy, education and technology directly bear on the strength and competitiveness of a country. To cope with the challenge of knowledge economy, every country must modernize their education industry through informatization. Some countries have already applied modern information techniques to reform and promote education $[2,3]$.

The importance and strength of education informatization have been widely recognized. However, there are not many teaching practices that utilize education informatization [4]. In fact, lots of teachers have realized that the conventional teaching model often restricts students from fully developing their capabilities, rather than bring them benefits. In this information age, a well-qualified teacher should be able to informatize his/her teaching with the most cutting-edge techniques, such as big data 
and cloud computing, and familiarize students with the informatized and "high-tech" teaching process. Many innovative teaching methods have integrated the latest information technology into teaching, namely, massive open online courses (MOOCs), micro-courses and student portrait. If implemented, these methods could create a highly-informatized, intelligent education environment, and thus advance and modernize the education industry $[5,6]$.

As an integral part of China's national strategy on informatization, education informatization has far-reaching significance for higher education development and talent training [7, 8]. There are many defects with the current education model in Chinese universities: rigid evaluation criteria, delayed assessment and poor utilization of resources [9, 10]. Many of these defects arise from the lack of information techniques. For example, the international trade department in most Chinese universities fall short in many aspects of teaching process evaluation. There is not yet a wellestablished standard to evaluate students' capabilities in the teaching process based on the teaching contents, not to mention enhancing their problem-solving abilities [11, 12].

To overcome the said defects, this paper introduces the latest information techniques into the teaching of international trade, designs an individualized teaching system based on student portrait, and constructs an intelligent evaluation system of the teaching process [13]. Finally, the current training model of international trade students was reformed based on our evaluation system.

\section{Design of Individualized Teaching System}

The student portrait is an intuitive tool to describe the learning conditions of each student, such as academic achievement, learning interest and learning desire. The accuracy of the student portrait directly affects the quality of teaching programs, learning plans and teaching methods $[14,15]$. It is possible to individualize the teaching process based on well-designed student portrait.

The individualized teaching focuses on the needs of the individual student. Each student is given a tailored learning plan to improve their acquisition and application of new knowledge, and to promote their character development. The importance of individualized teaching is recognized by most Chinese universities. Therefore, this paper attempts to design an individualized teaching system based on student portrait.

\subsection{Design process}

Considering the features of individualized teaching, the author put forward a threestep design strategy for student portrait.

Step 1: Setting up a library of teaching resources

The key to the design of study portrait lies in the teaching resources. These resources should be prepared collaboratively by leading teachers and experts of international trade, in the light of the teaching features of this major. Firstly, the knowledge points must be sorted out and combined into a scientific knowledge system. On this 
basis, the relevant knowledge points should be combined flexibly into resources packages for the specific teaching needs. Meanwhile, a knowledge map of the major should be prepared, and used to set up the library of teaching resources. The contents in the library can be reorganized by teachers. Moreover, every teacher is allowed to upload his/her resources to further enrich the library.

Step 2: Creating an adaptive learning system

An adaptive learning system needs to be established at the front end to provide students with individualized learning services. The system devises a teaching strategy for each student according to the information on his/her student portrait, such as objectives, learning style and cognitive level. The strategy involves fully individualized learning paths and resources.

Step 3: Realizing cross-platform compatibility

The front-end adaptive learning system must be compatible with multiple mobile devices, ranging from smartphone to tablet computer, allowing students to use our system anywhere anytime.

\subsection{System features}

The structure of the adaptive learning system-based on student portrait is illustrated in Figure 1 below.

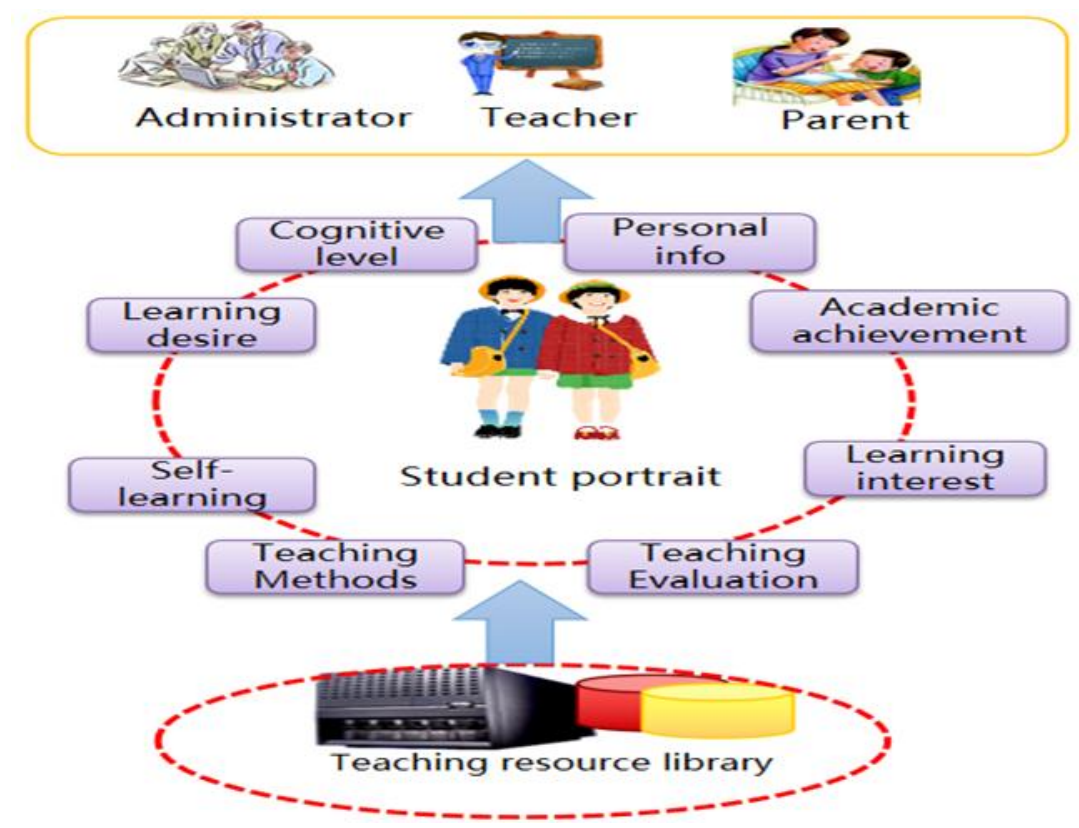

Fig. 1. Structure of the adaptive learning system

The data flows through the system in a closed loop. The closed-loop pattern makes it possible to constantly revise the student portrait, the learning object, the learning 
path, the learning model and the teaching model. In this way, the students can learn new knowledge in an adaptive manner.

The cloud infrastructure guarantees the normal operation of the system. The relevant hardware includes the database server, the file server, the load-balancing server, etc.

The data layer provides the system with data resources, such as questions, test papers, files, users and knowledge points. The data resources are classified accurately, and the metadata is managed according to strict rules, making the data access rational and effective.

The application layer is the gateway of the individualized teaching system. On this layer, an integration mechanism is deployed to effectively organize and fuse the relevant application systems.

Overall, the individualized teaching system operates in a safe and standard mode. The entire system is managed by a multi-dimensional model, offering different services to users with different rights. The system provides teachers, students and administrators are provided with different operation modes. After login, each type of user can enjoy the functions and access the resources that are designed specifically for them.

\subsection{Individualized teaching system integrated into teacher education}

The current teacher education does not pay attention to informationization or digitization, but the importance of informatization as a core skill in the teaching process of each major is constantly improving. Although the informationization ability has been widely recognized, teaching training based on informatization is still not very common. Although teachers have realized that the current teaching model does not allow students to fully benefit, it limits students to develop their information capabilities and skills. That is mainly due to the fact that the teachers themselves are not trained in the system. However, the information literacy of teachers will become the professional standard of teachers in the near future. However, the essence of information literacy should be an educational concept, not a technical tool.

In order to prepare students to adapt to a constantly "technical" world, educators, both now and in the future, need to continually strengthen their skills in the face of austerity. There is currently a lack of technology-related personalized teaching systems integrated into the teacher training process. Researchers have found that many teachers' pre-employment training systems simply do not help them acquire the appropriate technology. In addition, most of the teacher training focuses on how to operate the equipment, rather than how to effectively integrate technology and teaching.

Nowadays, many new technologies are deployed in schools in the absence of effective teacher training, resulting in lower system usage. Even if a teacher is willing to use new informatization or digitization tools, he may not be able to help with the maintenance of the equipment, because there are very few technical support staff in many areas, or simply not. It is precisely because of these problems that the corresponding solutions are proposed to integrate the personalized teaching system into teacher education. 
Application of Individualized Teaching System: Personalized learning system construction refers to a series of educational projects, learning design, teaching methods and subject support strategies implemented to meet individual, special learning needs, interests, aspirations, or cultural backgrounds. Although the need for personalized learning is real, there is no way to fully satisfy existing technologies and practices. The continuous improvement of the student-centered learning philosophy has also promoted the development of new technologies. The development of technology can provide educators with more choices to support personalized instructional guidance. Online learning and adaptive learning technologies are enabling learners to make intelligent adjustments to their learning processes. However, the current operating mechanism of higher education does not have a student-centered education system.

The goal of a personalized learning model is to allow learners to determine their learning strategies and steps. Advances in technology, especially with mobile smart terminals and adaptive learning environments, have enabled student-centered learning. Education based on student energy efficiency seems to be an endless solution, and this model ensures that students truly reflect their knowledge of accurate, measurable, and transferable skills. Students receive differentiated support based not only on their individualized learning needs, but also on the application and innovation of knowledge and their character development. The assessment of the skills acquired by the students should be a positive and meaningful experience for the students.

Although some progress has been made in the definition of personalized learning concepts, technical tools, and integrated models that support personalized learning, the above content still requires further understanding and evaluation. We can be sure that the biggest limitation to the individualized learning process and the true potential of personalized learning is that schools must improve their standardized test scores. Personalized learning requires a variety of school configurations. Bright, open learning plazas are group learning spaces equipped with display devices. Students have a very rich selection of activities every day, and teachers guide students through flexible feedback from the system. By integrating a hybrid learning approach, students can access their learning resources at any time.

Promotion of personalized teaching innovation: At present, many schools do not have the ability to integrate personalized teaching innovation into the mainstream of schools. That's because innovation comes from an environment where you can freely try and implement new ideas. But the operating mechanisms of existing schools are still changing in a top-down manner, and existing incentives rarely encourage innovative approaches and practices in teaching and learning. Therefore, it is even more difficult to implement teaching innovation on a large scale and sustainably. This reality has led many educators to become very frustrated with the rigid constraints of the school, and even desperate for the expectations of change. Then, in order to successfully promote teaching innovation, we must first remove those restrictive policies, secondly, require a large amount of funds, as well as superior leadership, and finally a strong practical assessment. Although there are very few models to support individualized teaching innovation, some places are now paving the way for large-scale implementation and promotion of new teaching models. 


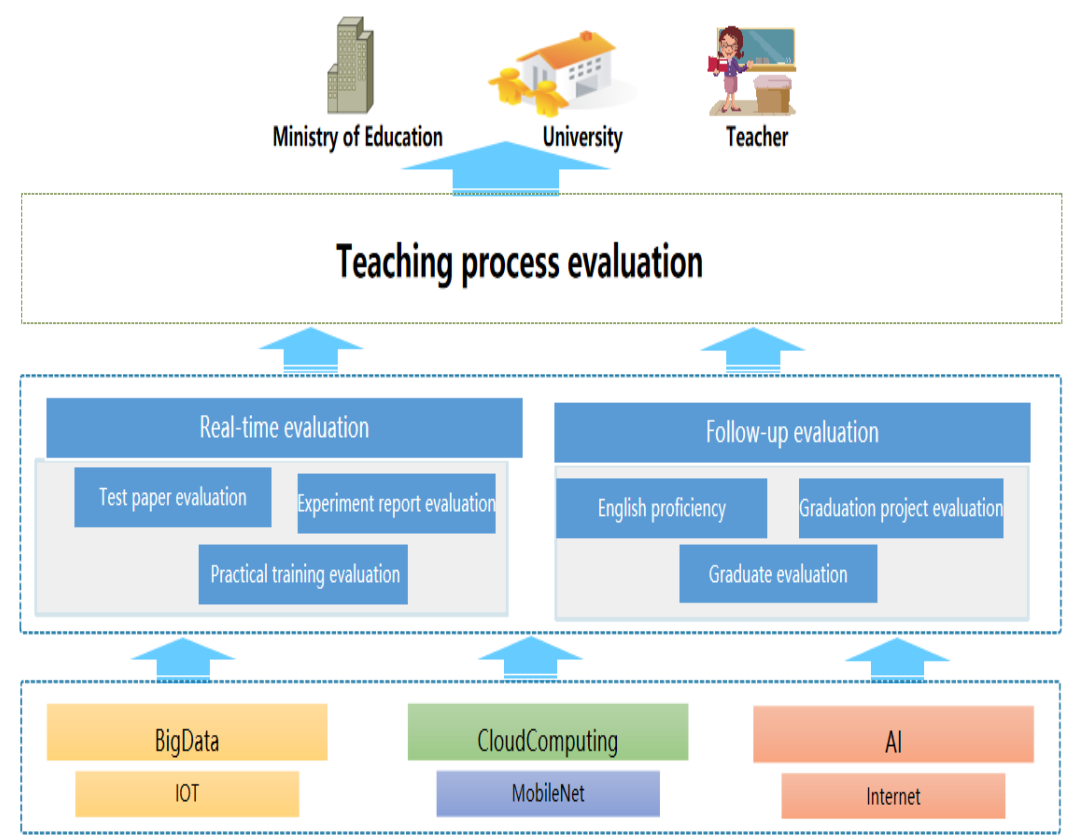

Fig. 2. Structure of teaching process evaluation system

\section{Construction of Teaching Process Evaluation System}

According to the demands of Chinese universities, this subsection constructs an evaluation system targeting the teaching process of international trade. As shown in Figure 2, the established system consists of two evaluation mechanisms: real-time evaluation and follow-up evaluation.

\subsection{Based on the new generation of information technology teaching methods}

Test paper evaluation: The teaching effect is evaluated through the analysis on the questions before the exam and the test scores after the exam. The teachers of international trade are enabled by an intelligent test paper analysis system to evaluate the mastery of basic knowledge, assess the learning ability and judge the performance of each student. On this basis, the teachers can improve the teaching method to arouse the enthusiasm of every student.

Experiment report evaluation: The teaching effect is also evaluated based on the students' reports right after experiments. The teachers of international trade should review and appraise every report to learn about the practical and innovation abilities of each student, and then make corresponding improvements to the teaching practice.

Practical training evaluation: The teachers of international trade must carefully arrange the practical trainings according to the syllabus. During the training, they 
should observe whether the students could apply what they have learned and judge if the application results are correct. In addition, the results should be graded into five levels: excellent, good, general, qualified and disqualified. Needless to say, the training reports should also be fully reviewed by the teachers.

\subsection{Follow-up evaluation}

English proficiency evaluation: International trade students should have a good command of English. Their English proficiency is an important indicator of the teaching effect. In our evaluation system, the English level of international trade students is mainly evaluated based on their scores in College English Tests Band 4 and Band 6, two national English language proficiency tests in Chinese higher education institutes, and often used by institutes as one of the criteria for their graduates obtaining degree diploma.

Graduation project evaluation: The graduation projects (e.g. graduation theses) of international trade students are supervised by teachers according to the process management manual. Each week, every student meets their tutors at least twice to discuss about the projects. The projects are evaluated by the defense committee. The evaluation results demonstrate the teaching effect on each graduate.

Graduate evaluation: Every year, the international trade department carries out follow-up surveys on the new graduates, including questionnaires, telephone interviews, etc. The graduates are fully evaluated based on their jobs, wages, and satisfaction of the teaching plan.

\subsection{Significance of the teaching process evaluation system}

The teaching process evaluation system sheds important new lights on how to improve the teaching effect of international trade. The evaluation results are of great value to students, teachers and administrators.

- The evaluation system can diagnose each student from multiple angles (e.g. knowledge, skills and competence). Through the evaluation, the students can learn about their strengths and weaknesses, as well as capabilities and potentials. On this basis, they can make reasonable plans for future studies and career.

- With the aid of the evaluation system, the teachers can learn about the features of each student scientifically, instead of relying on experience, and revise their teaching methods for each student.

- The administrators can obtain evaluation reports on each university and each region, correctly judge the teaching quality of each teacher, and roll out rational education policies in the future. The example of the evaluation is shown in Figure 3. 


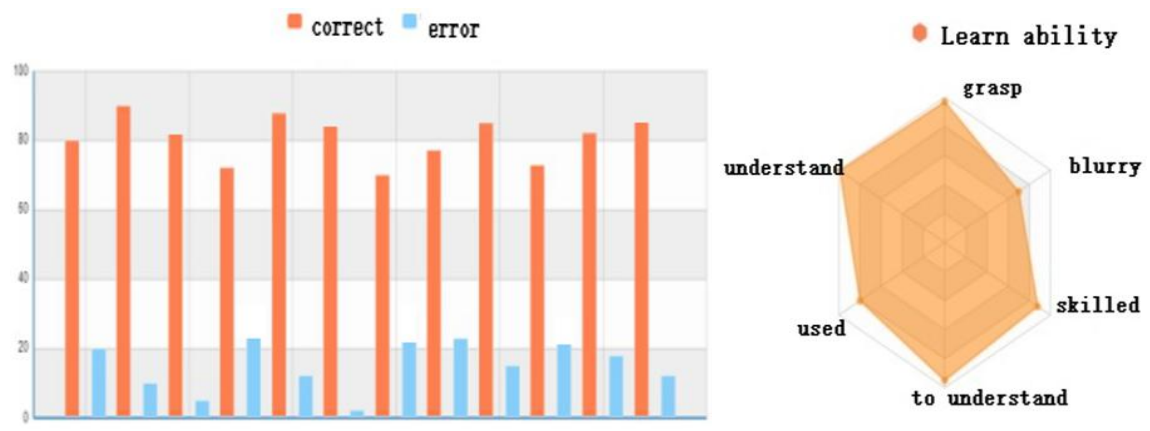

Fig. 3. The evaluation examples

\section{Reform of Talent Training Model}

The students majoring in international trade should have innovative thinking, global vision and teamwork spirit. Considering this requirement, the author put forward several suggestions on the reform of talent training model for international trade department based on the macro-quality evaluation system of Chinese universities, the established individualized teaching system, and the proposed teaching process evaluation system.

\subsection{Measured based on the macro-quality evaluation system}

The international trade department should develop quality standards for each link of the teaching process, under the macro-quality evaluation system of the university.

Course design: The syllabus should be formulated and revised regularly to clarify the quality requirements on each course, and provide the evaluation criteria for the teaching behavior and learning effect of each course.

- Change the structure of the course: increase the experimental class, promote the connection between theory and practice through hot issues and case analysis, and focus on improving students' various professional abilities.

- Promote teaching reform: arrange homework before class, communicate with students, share learning experiences and experiences, and learn about mastering students' learning in communication and communication.

- Innovative teaching methods: Using modern information technology, through WeChat or QQ, students are arranged to collect data through multiple channels before class, and discuss and case analysis in class and offline, which greatly improves the efficiency of teaching and the enthusiasm of students. Students' self-learning ability and ability to analyze problems and solve problems.

(2) Classroom teaching: Considering the teaching and research activities, the quality of classroom teaching should be controlled from the following aspects: prepa- 
ration, organization, contents, methods, homework assignment and homework correction.

During the course of the class, conduct discussions with the students, guide the students to collect relevant materials, and deeply understand the application of relevant theories in practice, so that students can search for information and think questions with questions, and share their learning experiences and experiences through collective debate in class. Teachers will give further explanation based on the sharing of students.

Exam design: The exams are an important means to judge the teaching quality. The international trade department must clearly stipulate the questions and modes of exams, and the ways to evaluate and analyze the answers.

Course examination consists of the usual scores and final scores in two parts. Course focuses on learning assessment process assessment, usually increase the proportion of test results, usually results from the exercise courses, course experiment, course discussions, extracurricular composition; courses include a final assessment exam noodles, reply, case studies, course papers; which course experiment Including experimental design, experimental operation, experimental report and other forms. The questions are divided into objective and subjective questions to examine students' ability to master and apply basic knowledge and their ability to innovate. The types of questions include fill-in-the-blank questions, multiple-choice questions, judgment questions, essay questions, and analysis questions. The course examination requires is pass both the usual scores and the final scores.

Graduation project: The department should establish a standard for the quality of graduation project, covering topic selection, tutor assignment, acceptance, review, defense and appraisal.

Graduates of this major have a wide range of employment, involving government agencies, institutions, banks, insurance companies and other enterprises. In recent years, the enterprise resources of the e-commerce school-enterprise alliance have signed a number of off-campus practice base agreements to provide internship opportunities for students, and from the follow-up visits to graduates in recent years, the number of students employed in cross-border e-commerce enterprises is higher.

Practical training: The results of practical training should be strictly controlled. The quality requirements on experiments, internships, and other links must be clearly defined.

Encourage students to participate in innovation and entrepreneurship competitions and training programs for college students at all levels to improve the cross-border ecommerce practice skills. In addition, combining scientific research with professional teaching, carrying out scientific and technological innovation activities, encouraging students to participate in teacher research projects, actively applying for innovation and entrepreneurship projects at all levels, and publishing relevant academic papers to promote innovation. 


\subsection{Measures based on the individualized teaching system}

According to student portrait and the individualized teaching system, the international trade department should cultivate talents with comprehensive abilities, innovation capacity and global vision. The graduates from the department ought to master the theories on economy and the skills on international trade. The following suggestions were presented on the training model of international trade students:

- The teachers of international trade should focus on cultivating the following abilities of their students: the mastery of basic theories on international economy and trade, and the ability to apply relevant theories to analyze the hotspots of international trade and the issues in economic field.

- The teaching program should ensure that graduates from this department process the skills, know the trends and be familiar with the rules of international trade.

- The training model should attach importance to the cultivation of global vision, English proficiency, cross-culture communication, and coordination skills.

- The international trade department should cooperate with international trade departments, foreign-funded enterprises and government agencies to provide students with more opportunities of practical training.

\subsection{Measures based on the teaching process evaluation system}

Several measures were proposed based on the teaching process evaluation system. These measures cover the main phases of the teaching process, especially on the course design.

Adding practical courses: The Cross-Border E-Commerce Practice should be introduced as a new professional course. The professional qualification certificate should be included as a teaching objective. The courses and syllabus must be designed according to the standards for the professional qualification test. The ultimate goal is that: more than $90 \%$ graduates could pass the professional qualification test.

Reducing theoretical courses: The course contents should be streamlined to increase the percentage of practical course in the curriculum system. The changes should be carried out without sacrificing the overall quality of the curriculum.

Increasing training sessions: More experimental courses should be opened to improve students' practical ability. The university should cooperate with enterprises to enhance the quality of practical trainings. The internships should be planned based on the interests and strengths of each student.

\section{Conclusion}

In This paper quantifies the teaching effects and guides students' learning in the department of international trade, based on the latest information techniques like big data and cloud computing. Specifically, the author put forward an individualized teaching system based on student portrait, designed a teaching process evaluation system, and gave advices on the talent training model of international trade depart- 
ment. The research findings shed new light on the evaluation and improvement of teaching effects in other majors.

\section{Acknowledgements}

This research is supported by Teaching Reform Project of Shenyang University (Project name: Research and Practice on the Construction of Cross-Border ECommerce Practice Teaching Based in Application-Oriented Universities; Grant No.: C25), and Liaoning Provincial Social Science Fund (Project name: Research on the Transformation and Upgrading of Traditional Foreign Trade Enterprises by CrossBorder E-Commerce in Liaoning Free Trade Zone).

\section{$7 \quad$ References}

[1] Bulut, O.M. (2018). The effects of merging student emotion recognition with learning management systems on learners' motivation and academic achievements. Computer Applications in Engineering Education, 26(5): 1862-1872. https://doi.org/10.1002/cae.22000

[2] Chen, G.D., Chang, C.K. (2018). Development and evaluation of a novel e-book interface for scaffolding thinking context to learn from writing examples. Interactive Learning Environments, 26(8): 1-26. https://doi.org/10.1080/10494820.2018.1427113

[3] He, X.Y. Zhang, W. (2018). Emotion recognition by assisted learning with convolutional neural networks. Neurocomputing, 291: 187-194. https://doi.org/10.1016/j.neucom.2018.0 2.073

[4] Abdulhameed. A, Abdullah, Ghulam A.M. (2015). Enhanced engineering education using smart class environment. Computers in Human Behavior, 51: 852-856. https://dx.doi.org/10.1016/j.chb.2014.11.061

[5] Albino. V., Berardi. U., Dangelico, R.M. (2015). Smart Cities: Definitions, Dimensions, Performance, and Initiative. Journal of Urban Technology, 22(1): 2-21. https://doi.org/10. $\underline{1080 / 10630732.2014 .942092}$

[6] Punnarumol, T. (2014). Ubiquitous Learning Environment: Smart Learning Platform with Multi-Agent Architecture. Wireless Personal Communications, 76(3): 627-641. https://doi. org/10.1007/s11277-014-1730-2

[7] Yang, J., Chen, C.H., Chang, M.J. (2010). Integrating video-capture virtual reality technology into a physically interactive learning environment for English learning. Computers \& Education, 55(3): 1346-1356. https://doi.org/10.1016/j.compedu.2010.06.005

[8] Kiavash, B., Rob, N., Wim, W. (2016). Data Fusion for Real-time Multimodal Emotion Recognition through Webcams and Microphones in E-Learning. International Journal of Human-Computer Interaction, 32(5): 415-430. https://doi.org/10.1080/10447318.2016. $\underline{1159799}$

[9] Kiavash, B., Rob, N., Wim, W. (2016). Towards multimodal emotion recognition in elearning environments. Interactive Learning Environments, 24(3): 590-605. https://doi.org/ $10.1080 / 10494820.2014 .908927$

[10] Ma, H., Wang, X.C., Zhang, G.Y. (2016). Research Hotspots and Trend Analysis of Learning Analytics in China based on Mapping Knowledge Domain. China Educational Technology and Equipment, 18: 1-3. https://dx.doi.org/10.3969/j.issn.1671-489X.2016.18.001 
[11] Robert C.K. (2014). Teacher efficacy in Teaching and Teacher Education. Teaching and Teacher Education, 44(11), 168-179. https://doi.org/10.1016/j.tate.2014.07.007

[12] Joana C., Teresa L., Margaret B. (2010). The quality of teacher-student interactions: Associations with first graders' academic and behavioral outcomes. Journal of School Psychology, 48(6), 457-482. https://doi.org/10.1016/j.jsp.2010.09.001

[13] Ravichandran, C.G., Selvakumar, R.R. (2016). Design and Implementation of Medical Image Fusion of Computer Tomography and Magnetic Resonance Imaging Using the Integrated Technique. Journal of Computational and Theoretical, 13(5): 2718-2725. http://doi.org/10.1166/jctn.2016.4907

[14] Cao, J.F., Chen, L.C. (2015). Fuzzy Emotional Semantic Analysis and Automated Annotation of Scene Images. Computational Intelligence and Neuroscience, 2015: 971039. https:// doi.org/10.1155/2015/971039

[15] Hwang, G.J. (2014). Definition, framework and research issues of smart learning environments - a context-aware ubiquitous learning perspective. Smart Learning Environments, 7(11): 1-4. https://doi.org/10.1186/s40561-014-0004-5

\section{Authors}

Yanan Zhao, female, associate professor, Shenyang University, PhD, School of Economics, her main research direction is cross-border e-commerce and international trade.

Article submitted 2019-09-11. Resubmitted 2019-11-03w. Final acceptance 2019-11-11. Final version published as submitted by the authors. 